$A P O B$

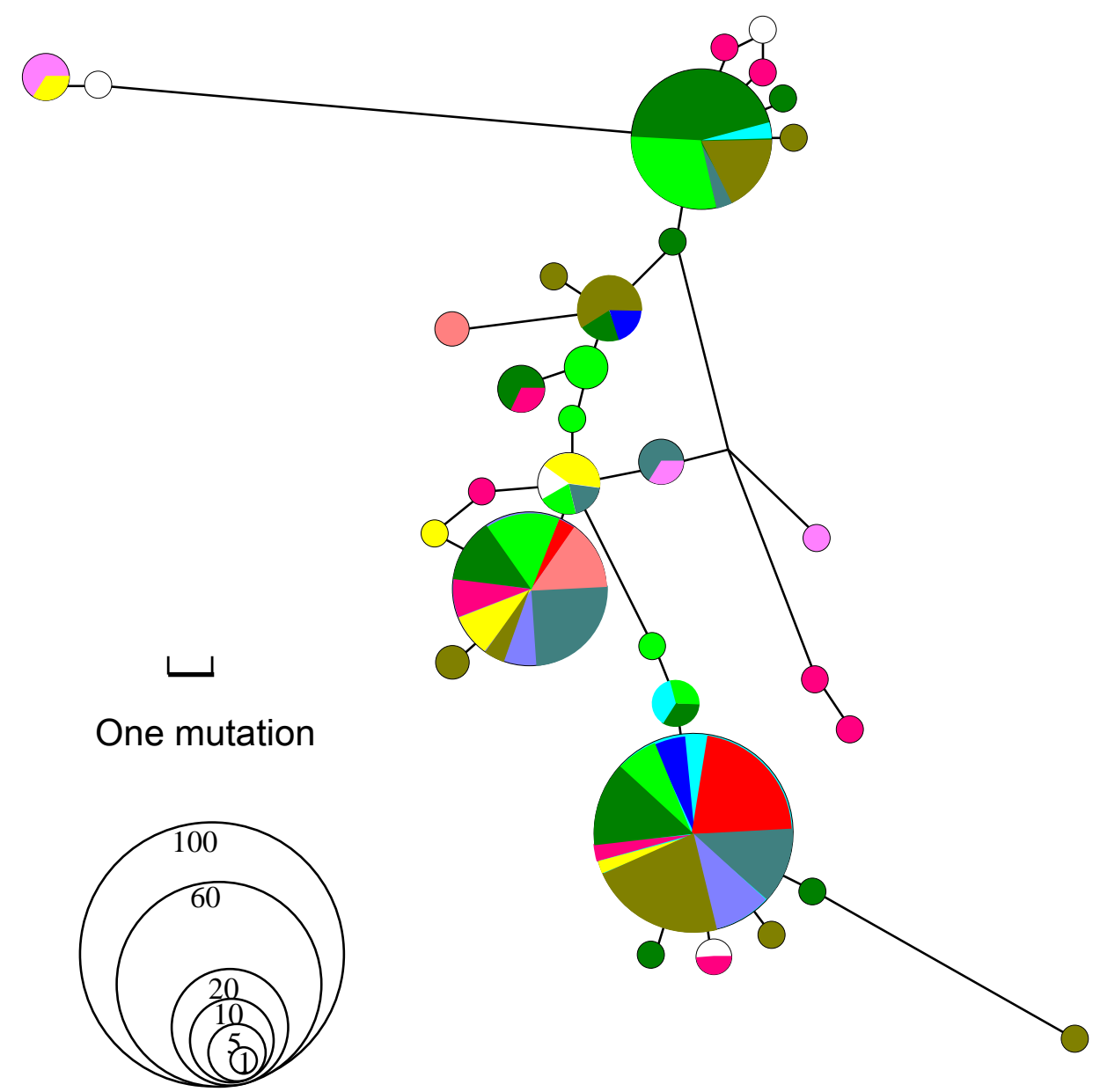

CASQ1
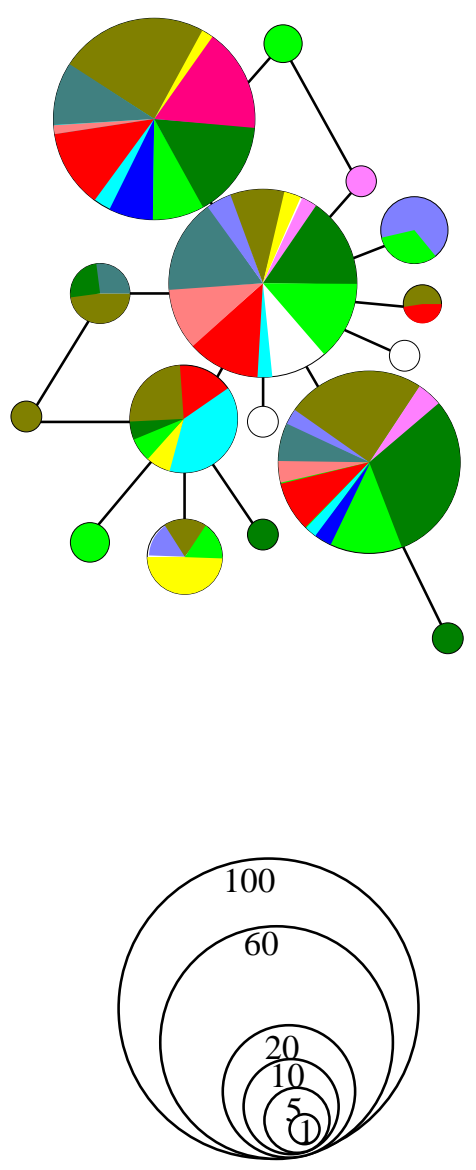

NEA UMYR DRYR URYZ MDYZ Mekong SC

\section{Wild boar}

Domestic pig

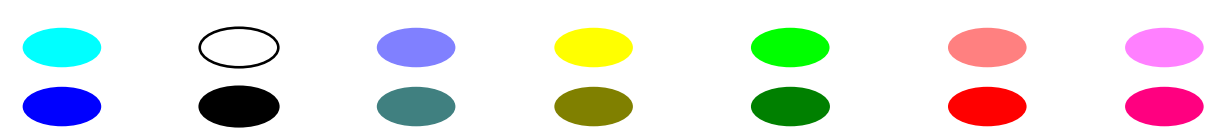



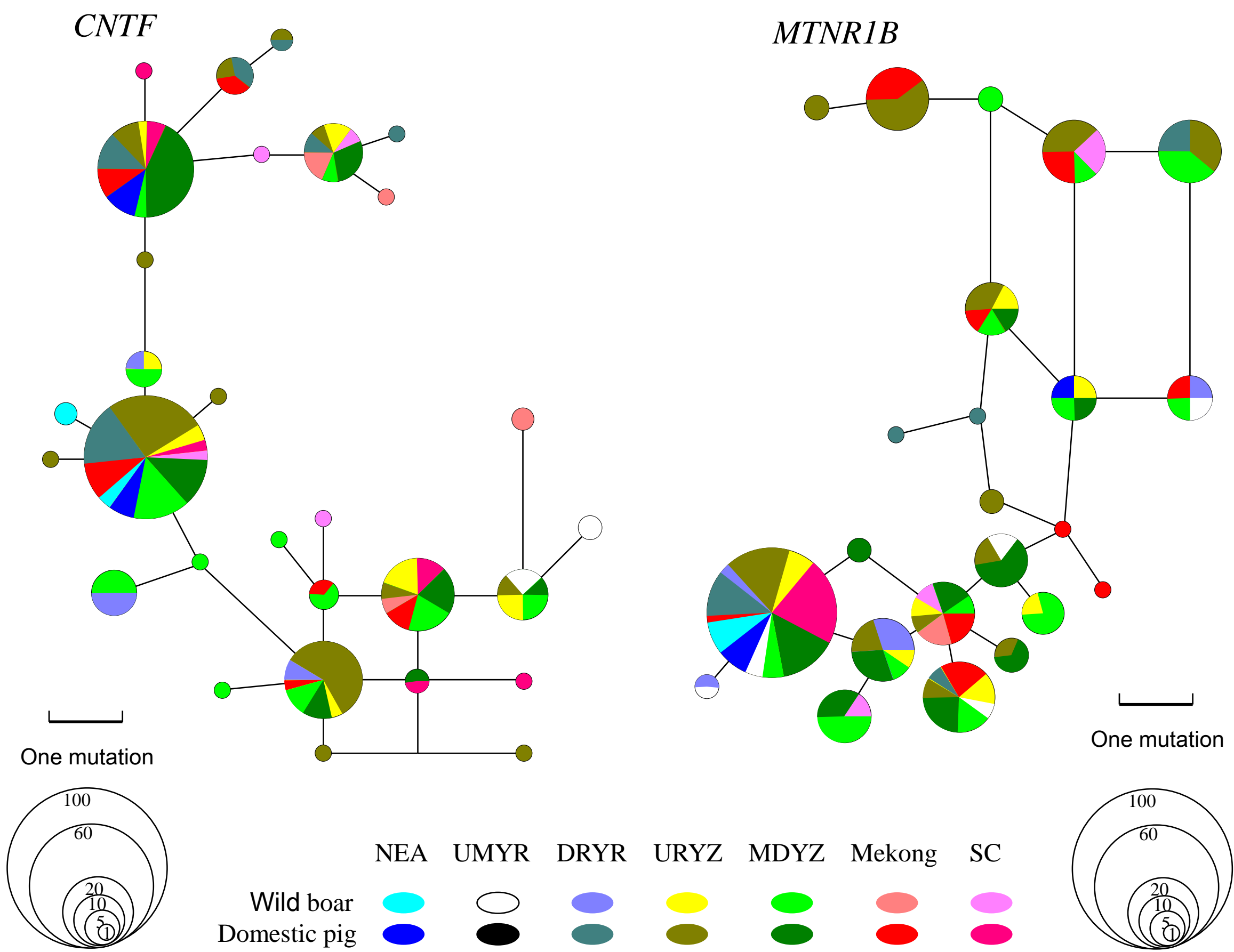

NEA UMYR DRYR URYZ MDYZ Mekong SC
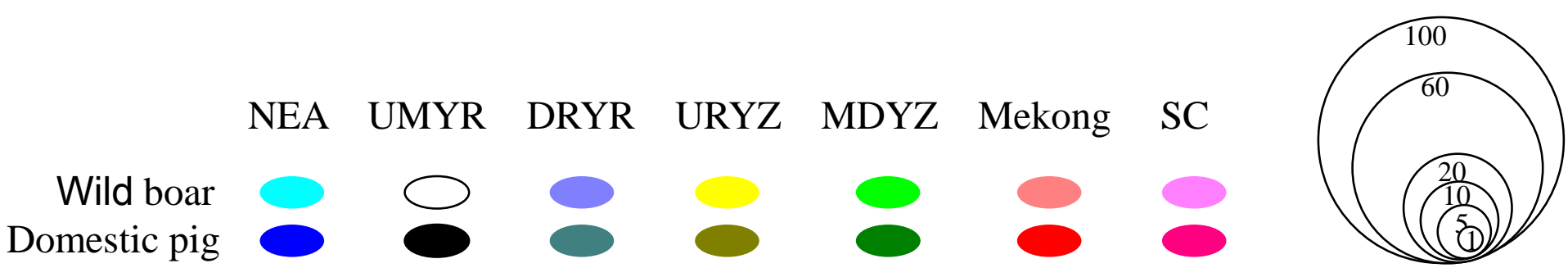

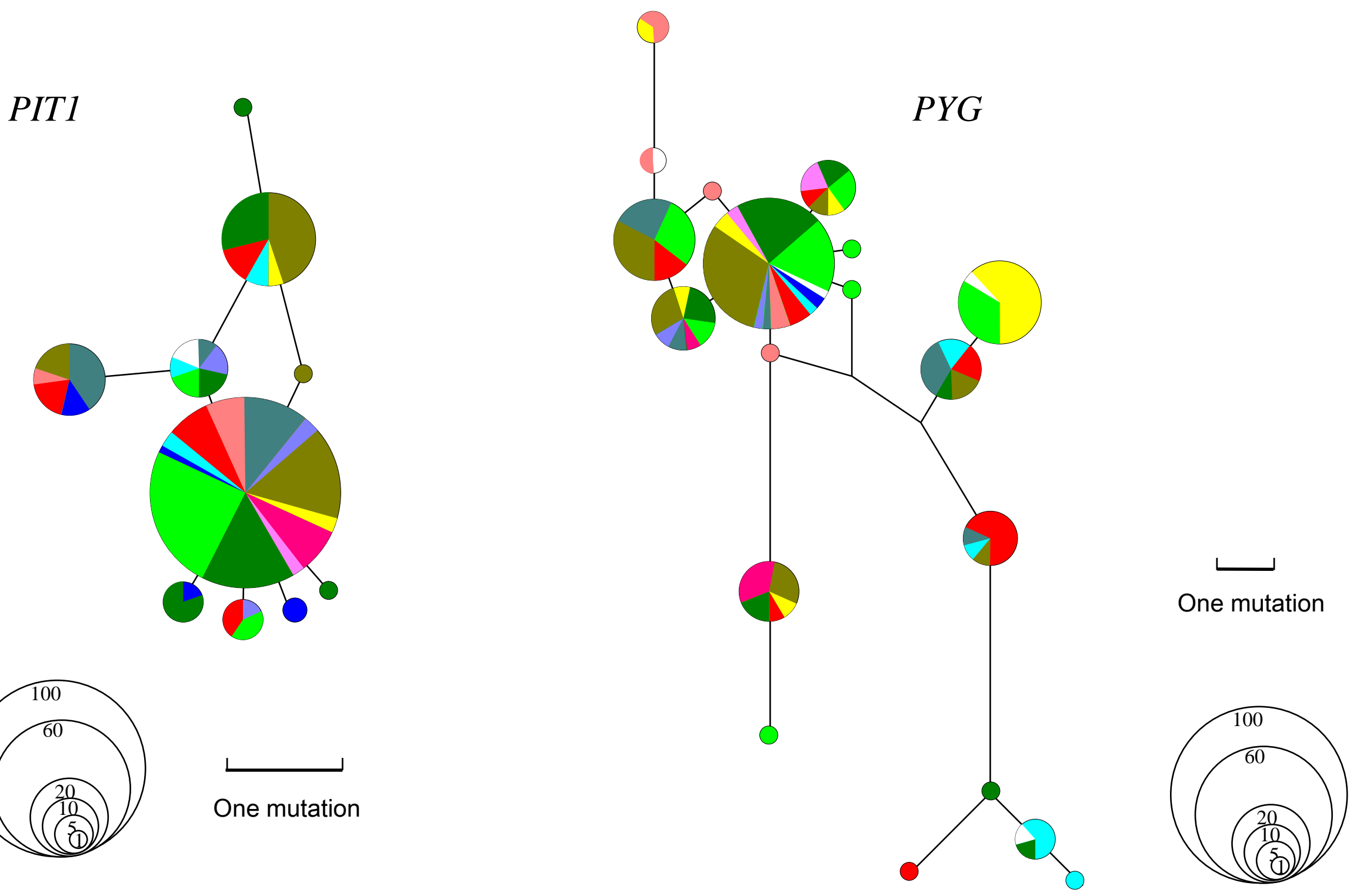

NEA UMYR DRYR URYZ MDYZ Mekong SC

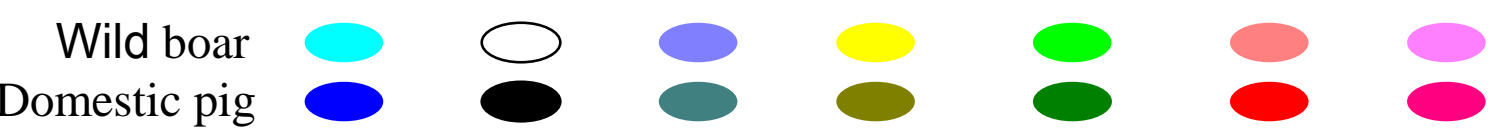



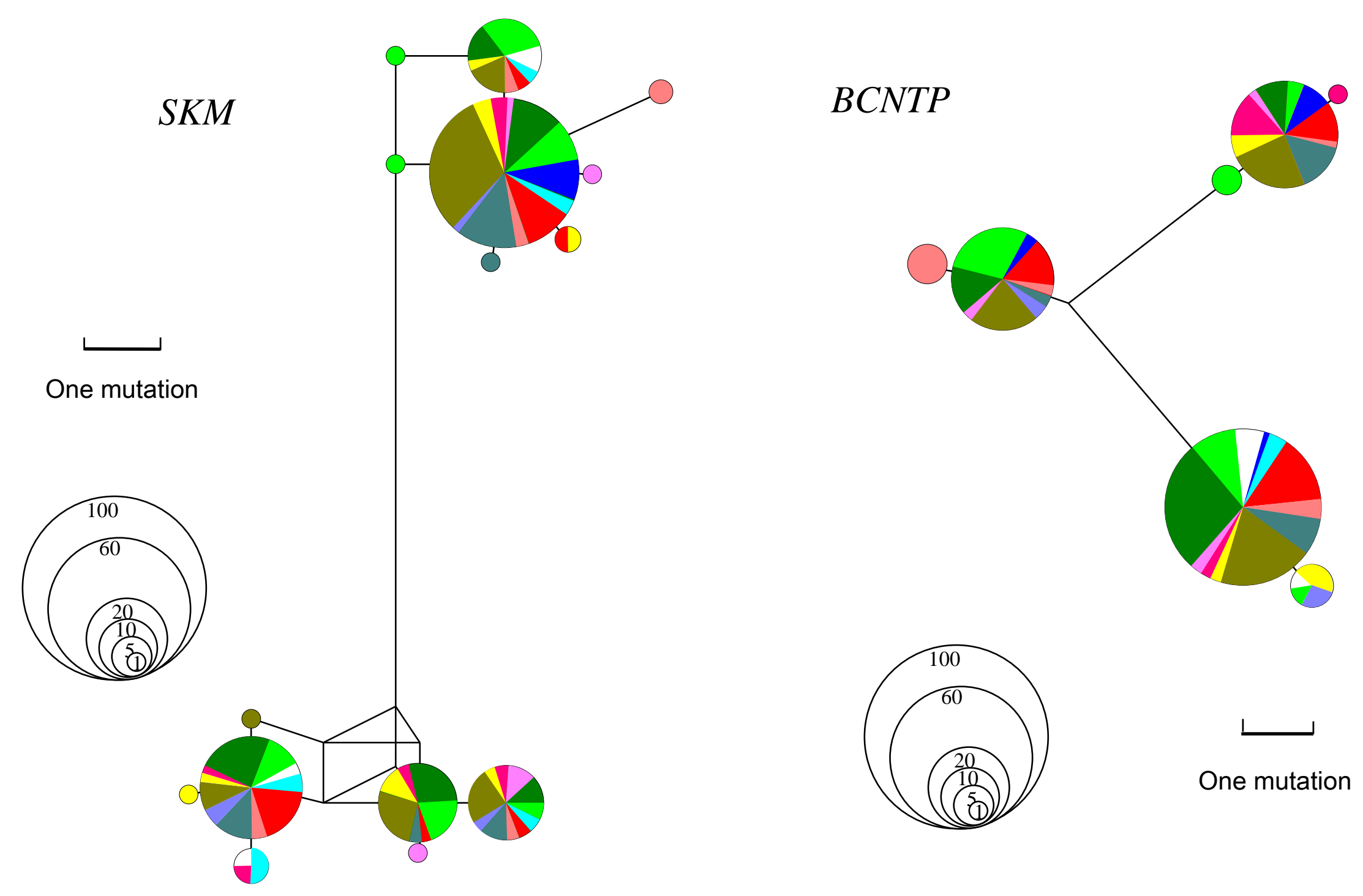

NEA UMYR DRYR URYZ MDYZ Mekong SC

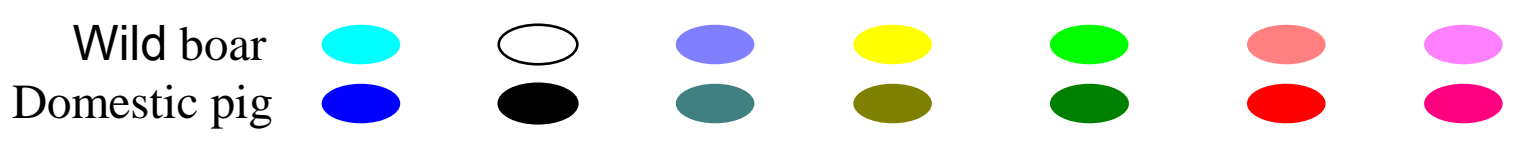




\section{$U C P 1 P$}
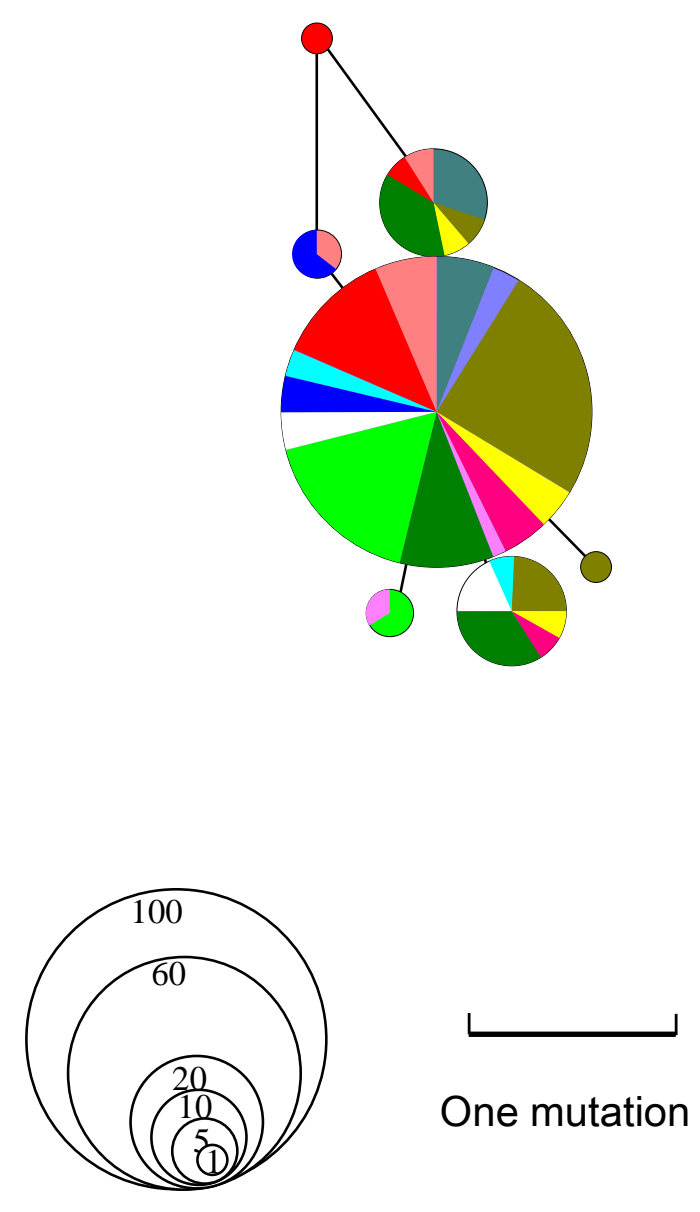

\section{$\mathrm{CH} 4$}
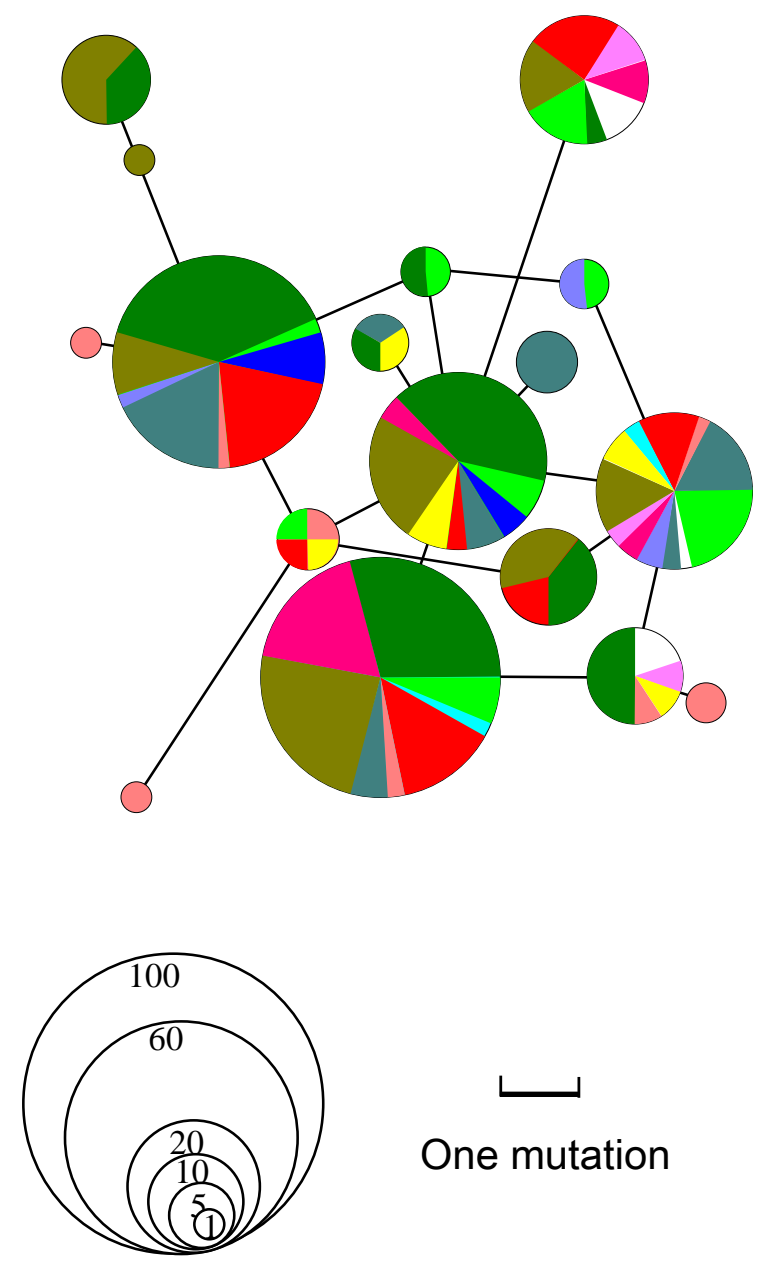

$\mathrm{CH} 7$

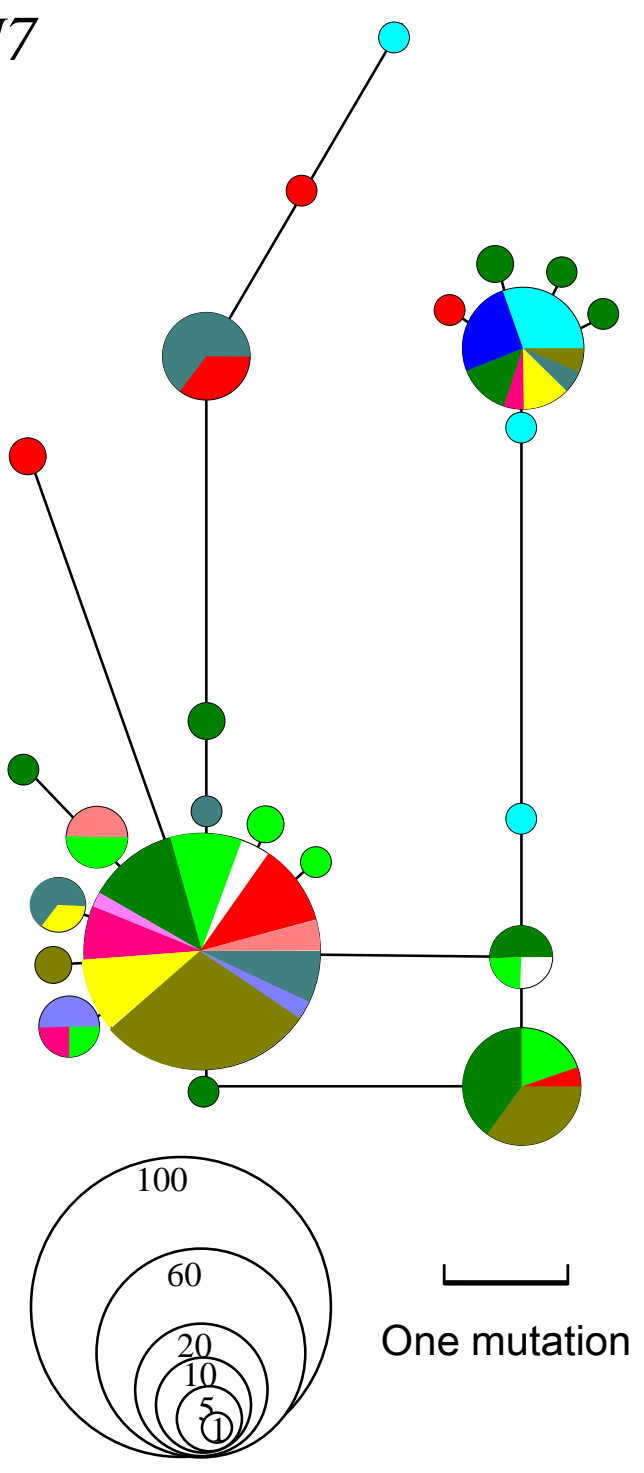

NEA UMYR DRYR URYZ MDYZ Mekong SC

Wild boar Domestic pig

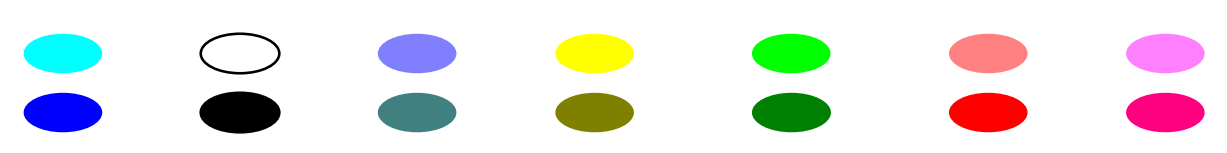



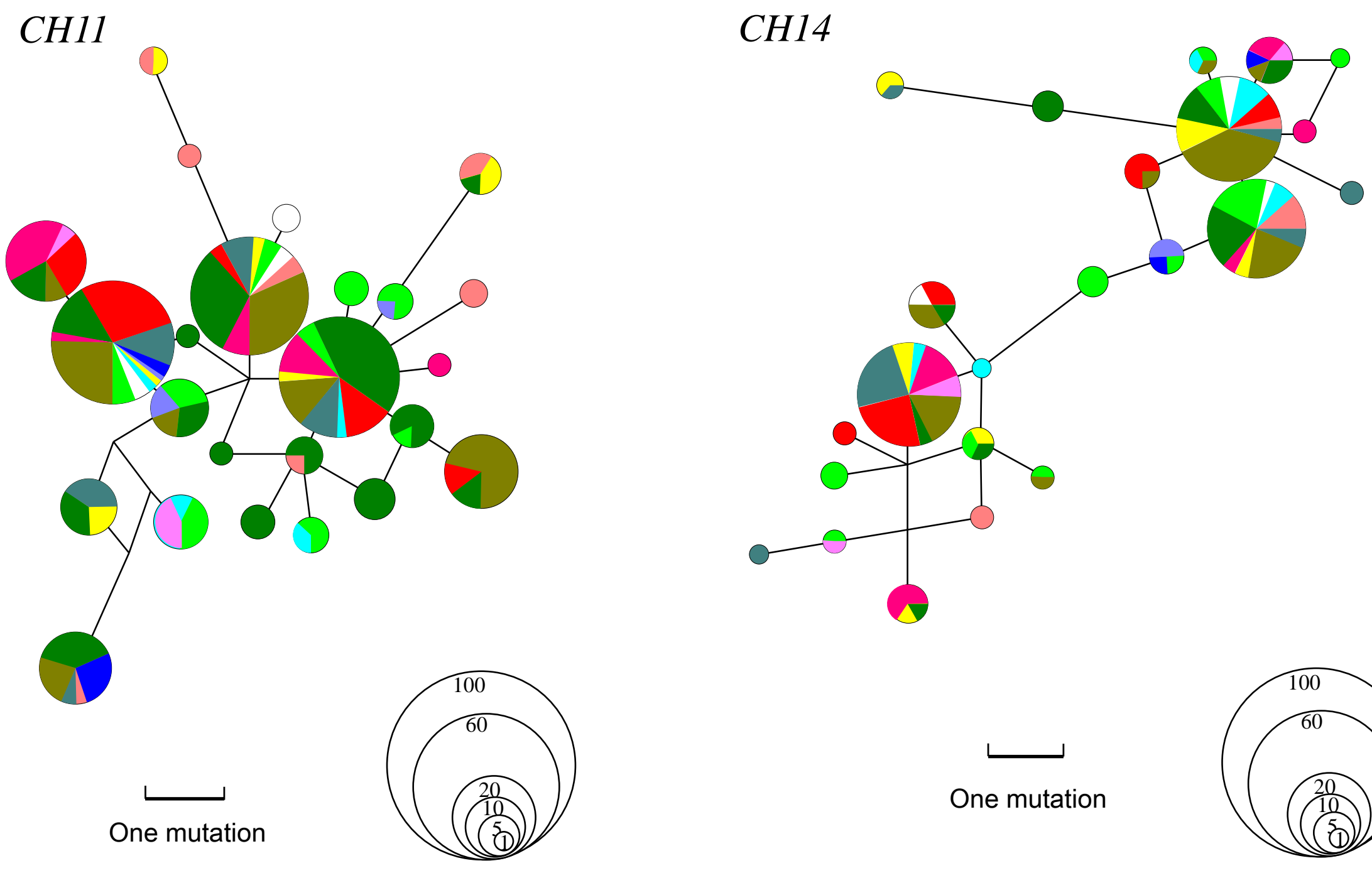

NEA UMYR DRYR URYZ MDYZ Mekong SC

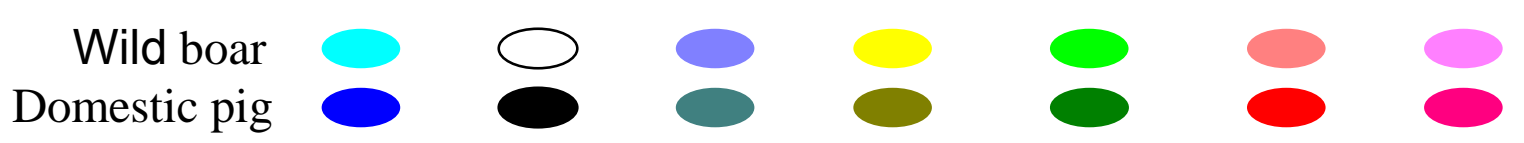


northeast Asia domestic pig Northeast Asia wild boar Domestic pig in region UMYR Domestic pig in region DRYR
Domestic pig in region MDYZ

Wild boar in region MDYZ

Domestic pig in the Mekong region

- Wild boar in the Mekong region
Domestic pig in South China

- Wild boar in South China

- Domestic pig in region URYZ

Wild boar in region URYZ $\square$ Other

Feral pigs

- Japanese domestic pig and ancient DNA

* Coalescent root type of haplogroup D1

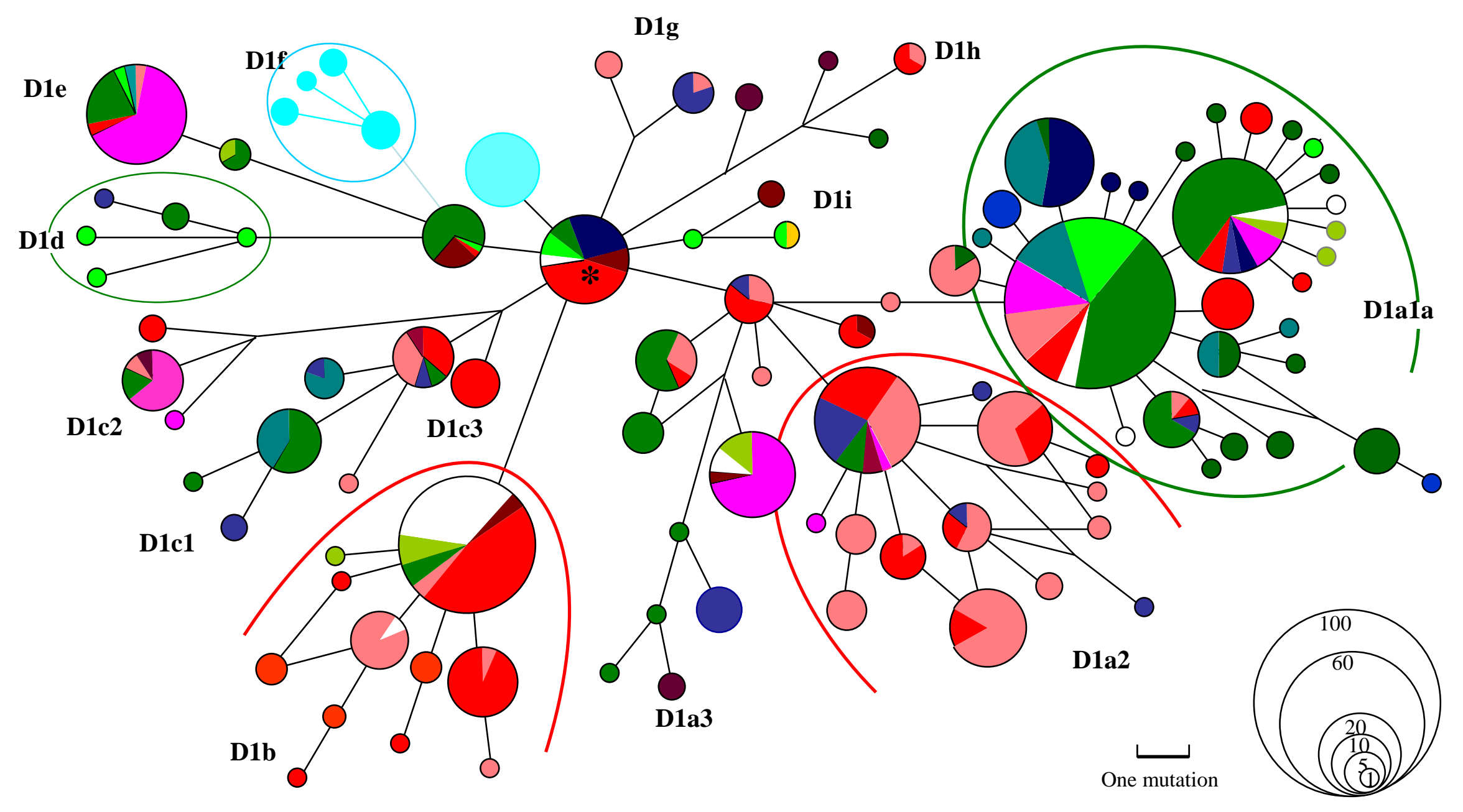

